\title{
A Multidisciplinary Diabetes Clinic Improves Clinical and Behavioral Outcomes in a Primary Care Setting
}

\author{
Shay Phillips, PharmD, BCPS, CDCES, BC-ADM, AAHIVP, \\ Jamayla Culpepper, MD, MPH, Madelyn Welch, BA, Katherine J. O'Hare, BSPH, \\ Willa Chen, BS, Yhenneko Taylor, PhD, William Anderson, MS, and Hazel Tapp, PhD
}

Background: The percentage of adults achieving hemoglobin A1c goals less than $7 \%$ remains a challenge. The study objective was to evaluate effects of a multidisciplinary approach on behavioral outcomes and mean change in A1c in immediate start (intervention) versus 6-month delay (control) groups at 6 months.

Methods: The study assessed 111 patients recruited from a safety-net primary care clinic with a pharmacist-led multidisciplinary team and found that the intervention improved mean A1c outcomes for patients with type 2 diabetes. A1c values were measured every 3 months, and a self-efficacy scale to measure behaviors was evaluated at baseline and 6 months.

Results: After 6 months from baseline, the intervention group showed an A1c decrease of 2.4 compared with the control group's 1.1 decrease. Mean increase in self-efficacy score in the intervention group at baseline versus after 6 months showed a statistically significant change $(P=.01)$ compared with the control group $(P=.26)$. Results revealed a post hoc association between A1c and PHQ-9 such that patients with higher baseline PHQ-9 scores experienced greater mean decrease in A1c. In the immediate start arm, mean A1c values decreased from 10.6 at baseline to 7.7 at month 12 . For the delayed intervention group, mean A1c values decreased from 10.2 at baseline to 9.0 after 6 months.

Conclusions: Use of a multidisciplinary clinic team in a safety-net primary care practice improved mean A1c control and behavioral outcomes for patients with type 2 diabetes as compared to control group. (J Am Board Fam Med 2021;34:579-589.)

Keywords: Behavioral Medicine, Depression, Family Medicine, Patient Care Team, Patient Health Questionnaire, Primary Health Care, Self-Efficacy, Shared Decision Making, Telemedicine, Type 2 Diabetes Mellitus

\section{Introduction}

If recent trends in diabetes prevalence rates continue over the next 50 years, future demographic characteristics of the US population will lead to

This article was externally peer reviewed.

Submitted 23 June 2020; revised 19 December 2020; accepted 21 December 2020.

From the Department of Family Medicine, Atrium Health Carolinas Medical Center, Charlotte, NC (SP, MW, KJO, WC, HT); Carmel Family Medicine, Atrium Health, Charlotte, NC (JC); Center for Outcomes Research and Evaluation, Atrium Health, Charlotte, NC (YT, WA).

Funding: This study was funded by Atrium Health.

Conflict of interest: None.

Corresponding author: Shay Phillips, PharmD, BCPS, CDCES, BC-ADM, Department of Family Medicine, Atrium Health Carolinas Medical Center, 2001 Vail Ave., Suite 400 Mercy Medical Plaza, Charlotte, NC 28207 (Email: shay.phillips@atriumhealth.org). dramatic increases in the number of Americans with diagnosed diabetes. The projected number of adults with diagnosed diabetes would increase from 22.3 million in 2014 to 60.6 million in $2060 .{ }^{1}$

This increased number can further contribute to the disproportionate amount of health care costs linked to care of patients with multiple chronic diseases. One of 4 total health care dollars spent in the United States goes to the medical cost of diabetes. ${ }^{2}$ Cost is complicated by comorbid conditions such as depression, where people with type 2 diabetes have a $24 \%$ increased risk of developing depression. Those with diabetes and depression have 4.5 times higher the health care expenditures than individuals without depression..$^{3-5}$ Discordance exists between money spent and the percentage of patients who maintain glycemic control. The percentage of 
adults achieving A1c goals less than 7\% only increased from $44.3 \%$ in 1999 to 2002 to $52.2 \%$ in 2007 to $2010,,^{6,7}$ highlighting a need to implement more effective health care strategies to improve glycemic control. One probable strategy involving implementation of self-efficacy-focused education may lead to reduced A1c, enhanced self-efficacy, and regulation of self-management behaviors. ${ }^{8}$

The use of multidisciplinary teams is widely recommended to improve diabetes management. To date, there are limited studies evaluating the feasibility and efficacy of this team care approach, ${ }^{9}$ especially in safety-net clinics that serve a greater number of patients who are uninsured. ${ }^{10}$ According to the 2020 Standards of Medical Care in Diabetes, the use of multidisciplinary teams including primary care physicians, nurses, dietitians, pharmacists, and mental health professionals ranks only as an expert consensus because of limited clinical data. ${ }^{11}$ Preliminary studies have shown that treatment of diabetes in multidisciplinary teams with pharmacists or behavioral health professionals is associated with decreased A1c concentrations ${ }^{12-15}$ and more rapid attainment of associated goals. Despite these data, gaps in evidence remain, especially with respect to long-term outcomes and intervention sustainability.

This article describes a multidisciplinary clinic approach to improving glycemic control and behavioral outcomes in a family medicine safety-net academic practice. The study objective was to evaluate the effects of a multidisciplinary approach on behavioral outcomes and mean change in A1c in patients with type 2 diabetes.

\section{Methods}

\section{Study Design and Setting}

This single-site, single-blind, prospective study used a randomized delayed-start design with 2 parallel arms. Randomization was done in a simple sequence where patients were randomly assigned to immediate start versus the 6-month delay group based on the random order in which they were referred to the clinic. This study took place at an urban family medicine practice housing a family medicine residency program, affiliated with a level 1 trauma center and teaching hospital that is part of Atrium Health, a large vertically integrated health care system with care locations in North Carolina, South Carolina, and
Georgia. The patient population attending the practice had the following demographics: 70\% African American, 20\% Caucasian, and 10\% Hispanic/ other. Approximately 1200 patients with diabetes visit this site, with $45 \%$ Medicare, $35 \%$ commercial insurance, $14 \%$ Medicaid, and 6\% self-pay or sliding scale. The Atrium Health Institutional Review Board approved this study.

\section{Intervention}

This clinic was held at most 3.5 days per month and virtual (interim care) took approximately 8 hours per week. Members of the multidisciplinary team included a clinical pharmacist, rotating physician champions, clinical care nurse coordinator, social worker, behavioral health counselors, nurses, family medicine and pharmacy residents, and a research assistant. ${ }^{16}$ The clinical pharmacist, who is a certified diabetes care and education specialist and board certified in advance diabetes management, served as team lead. Standard 5 of the National Standards of Diabetes Self-Management Education and Support was used to appoint members of the multidisciplinary team. ${ }^{17}$

\section{Participants}

Providers referred practice patients who were nonpregnant, $\geq 18$ years old with type 2 diabetes, with at least 1 of the following criteria: A1c greater $>8$, A1c $<8$ but with wide blood glucose variability, newly diagnosed, and/or new to diabetes injection therapy. Patients being followed by an outside endocrinologist or on insulin pump therapy were excluded. After a provider referral, a research assistant contacted the patient to assess readiness and obtain consent. Using a 10-point self-reported motivation score, patients were asked, "How motivated are you in getting better control of your diabetes?" Patients scoring 5 or higher were included in the study and received a $\$ 10$ gift card for participation.

\section{Outcomes}

The primary outcome was the mean change in A1c in the intervention versus the control group during the 6 months of follow-up. Because all follow-up visits did not occur exactly at 6 months, a window of 5 to 10 months was used to capture outcomes. Per protocol, after 6 months the delayed-start group was exposed to the intervention. A1c values were assessed at baseline and every 3 months during 
the study period. Baseline A1c values were obtained from the medical record using the value closest to the time of randomization if that time frame was less than 3 months. If greater than 3 months had elapsed, the A1c was measured at the first diabetes clinic appointment. The secondary outcome was change in self-efficacy scores from baseline to month 6 of follow-up. Self-efficacy was measured using the Stanford Self-Efficacy for Diabetes Scale. $^{18}$

\section{Procedures}

The study was powered to detect a mean difference of 1 percentage point in A1c between the intervention and control groups. ${ }^{19}$ To achieve $80 \%$ power, a sample of 104 (52 per arm) was required based on a 2-sample $t$-test with a standard deviation of $1.8 .^{20}$ A sample size of 28 was required to achieve $80 \%$ power to detect a 2-point difference in the secondary outcome of self-efficacy (range 1 to 10 ) with a standard deviation of $1.76 .{ }^{18}$ The target sample size was set at 140 to accommodate an anticipated attrition rate of $20 \%$.

Patients were randomized 1:1 to the immediate start or the 6-month delay arm using a randomization schedule. Immediate start patients (intervention group) were scheduled in the first available appointment in the multidisciplinary diabetes clinic. Patients assigned to the 6-month delay arm (control group) continued to receive standard of care from their primary care provider for a period of at least 6 months before being scheduled for the first available multidisciplinary diabetes clinic appointment (see Figure 1).

\section{Previsit Evaluations}

Two previsit evaluations, termed previsit assessments (PVAs), were designed to identify barriers to disease management such as nonadherence, treatment complications, and a patient's perception of quality of life. ${ }^{21}$ The first PVA identified barriers in medication adherence, access to care, social support, depression symptoms, food acquisition, nutritional education, and self-care behaviors (see Table 1). The second PVA assessed patient self-efficacy using a validated, modified, self-efficacy scale (SES), where questions measuring self-confidence in self-management behaviors were modified to be more diabetes-specific. ${ }^{22}$ Answers to both PVAs allowed visits to be tailored to patient-specific needs to strengthen confidence, problem-solving skills, and self-management. The SES was administered at the first visit and again at 6 and 12 months (see Table 2).

\section{Initial Visit}

Two business days before the scheduled appointment, a reminder call was placed to patients asking them to bring a completed nutrition, glucose, and exercise $\log$ to the visit. $^{23}$ To promote patient engagement and empowerment, eligible patients with $\mathrm{A} 1 \mathrm{c}<9 \%$ were introduced to shared decision making (SDM) $)^{24}$ and motivational interviewing, ${ }^{16}$ to emphasize the importance of patient preferences for treatment. SDM is a process in which the patient and provider are equally involved in determining a treatment plan based on the individual patient's preferences of prioritizing medication cost, symptom control, side effects, and frequency of medication usage. During the clinic visit, specific patient treatment goals were shared and discussed so both patients and providers were involved in each treatment step of diabetes management. ${ }^{25}$ Patients not meeting the A1c $\leq 9 \%$ eligibility criteria for SDM were reassessed throughout the study period for inclusion and continued to receive all other aspects of the study interventions.

The diabetes clinic visits incorporated depression screening and diabetes education with an emphasis on healthful eating and exercise. To assess the presence and severity of depression, the 9-item Patient Health Questionnaire (PHQ-9) was administered by a behavioral health counselor at the initial visit and periodically thereafter based on the baseline score. ${ }^{26}$ To promote self-care, a packet of educational materials highlighting specific components of the National Standards for Diabetes Self-Management Education and Support were explained. ${ }^{17}$ All patients received nutrition education tailored to individual cultural customs, current A1c, blood glucose trends and variability, body mass index, activity level, financial status, and food stability. Different variations of education included, but were not limited to, the plate method, Mediterranean diet, and an intensive lifestyle intervention based on the LOOK AHEAD study. ${ }^{27}$ Detailed information on healthful eating from the American Diabetes Association's position statement on nutrition was referenced when applicable. ${ }^{28}$ Nutritional education, with an emphasis on accountability and sustainable healthy eating habits for maintaining glycemic control, was provided at multiple visits. 
Figure 1. Study design flow chart. EMR, electronic medical record; PVA, previsit assessment; SES, self-efficacy scale.

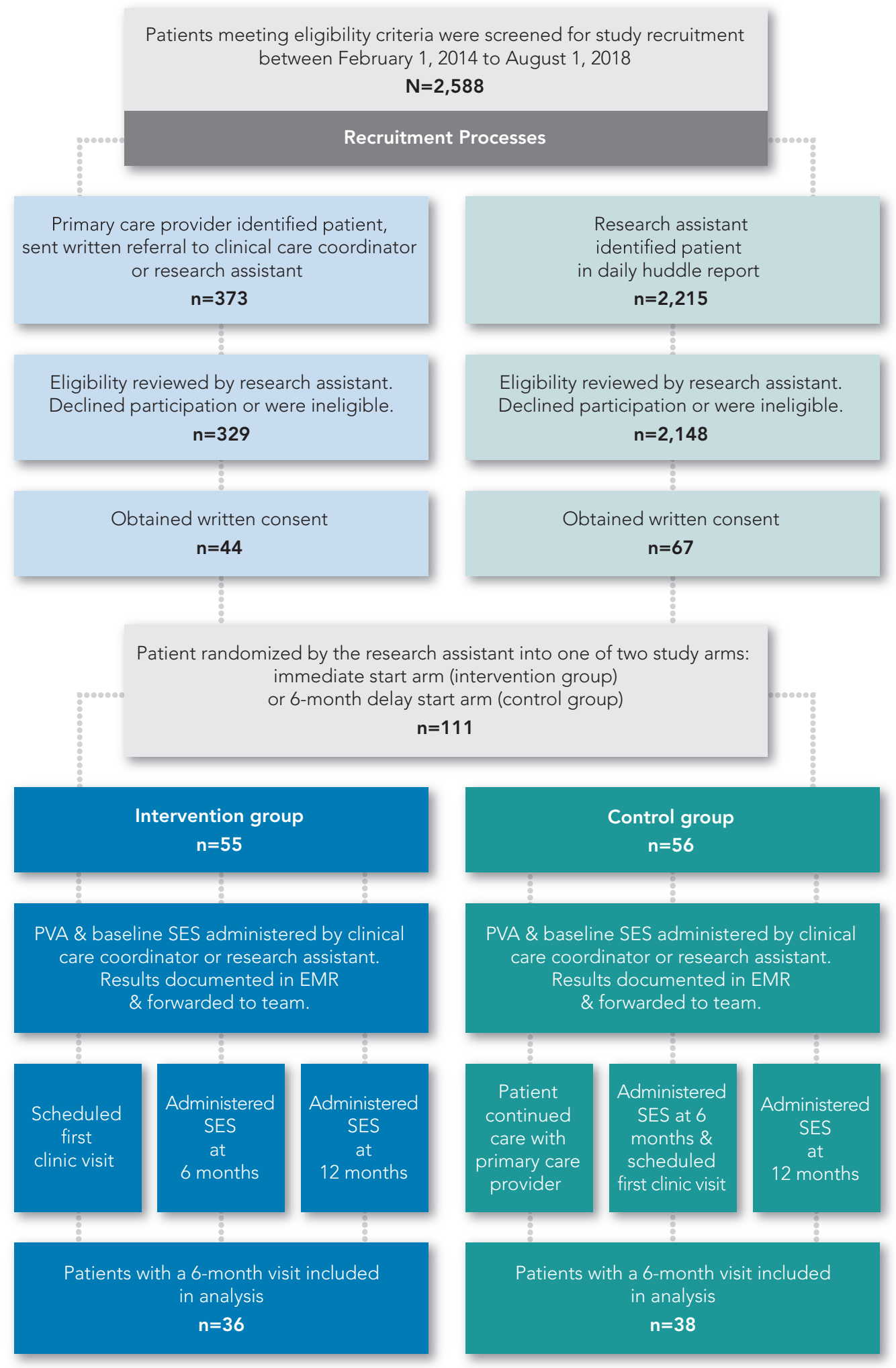




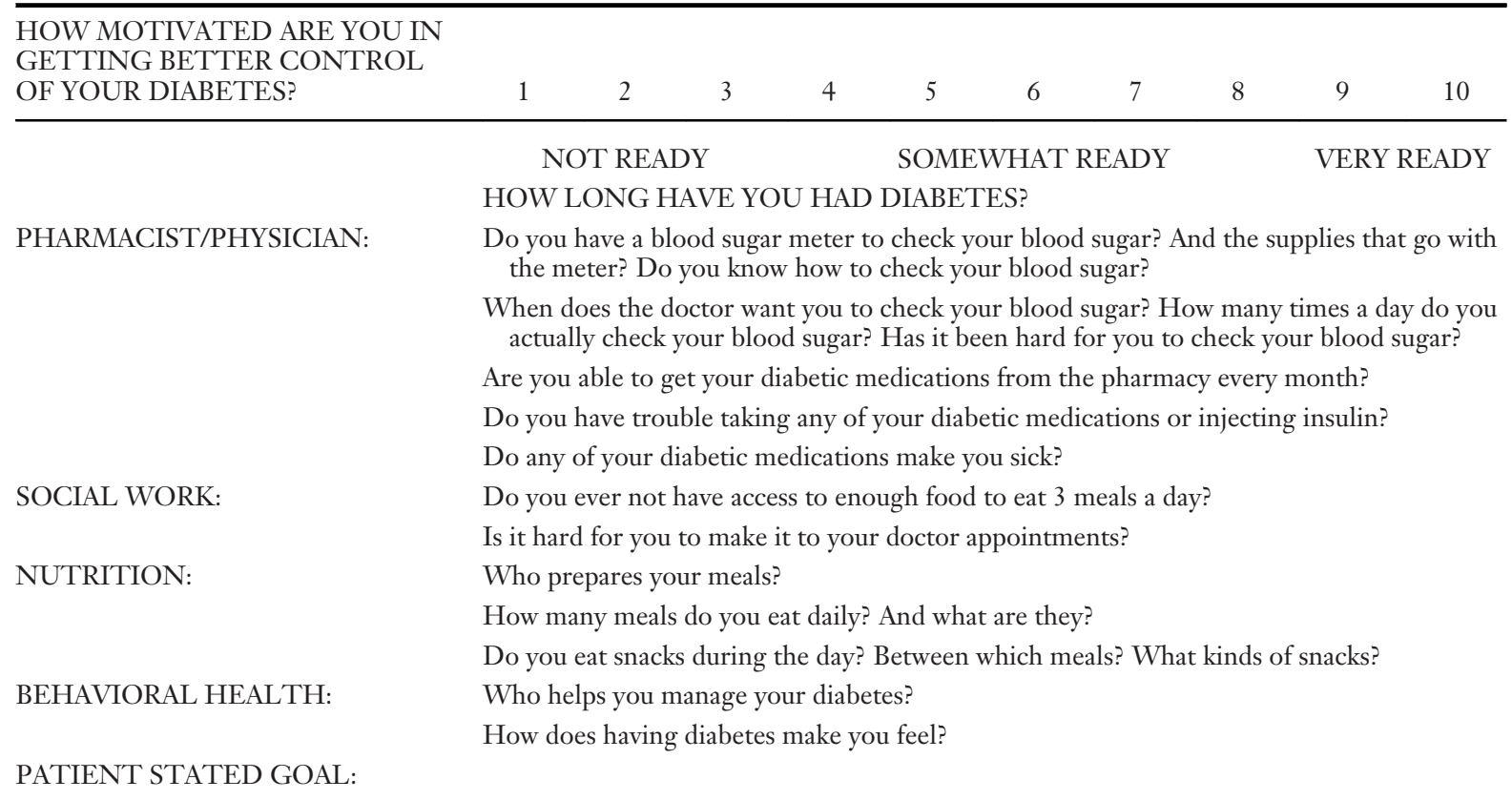

The following disease markers were measured when clinically appropriate: blood glucose, A1c, nonfasting lipid panel, basic or complete metabolic panel, urine microalbumin, and thyroid panel. ${ }^{11}$ Additional items addressed included foot examination, influenza vaccine, pneumococcal vaccines, hepatitis B vaccine, and screening for retinopathy and neuropathy.

\section{Follow-Up Visits}

Follow-up visits included repeat measurement of PHQ-9 every 4 to 8 weeks, clinically appropriate labs, vital signs, and office blood glucose as well as assessment of the patient's blood glucose recordings, exercise, and food logs. Medication therapy regimens were assessed at each follow-up visit for effectiveness, safety, tolerability, degree of weight neutrality, and affordability. Refill histories were obtained from community pharmacies to verify patients' self-report of adherence to the medication regimen. Behavioral therapy with a behavioral health counselor was offered. Patients started on or currently taking antidepressant medication were scheduled for frequent follow-up by the behavioral health counselor and the patient's primary care provider.

\section{Interim Virtual Care}

Interim virtual care for select patients, designed to improve access to care and provide frequent assessments and therapy intensification in between scheduled diabetes clinic visits, was coordinated by the clinical care nurse coordinator and executed by the clinical pharmacist. Inclusion criteria included patients with transportation challenges and at least 1 of the following characteristics: symptoms of hypoglycemia or hypoglycemia unawareness, wide blood glucose variability, and/or newly diagnosed or largely uncontrolled diabetes needing weekly insulin intensification. Each patient was called to obtain blood glucose values, and phone management for each patient continued until blood glucose and/or A1c values were within $1 \%$ of goal.

\section{Statistical Analyses}

Baseline demographic characteristics of patients in the 2 study arms were analyzed using Student's $t$ test, the $\chi^{2}$ test, or Fisher's exact test, as appropriate. Within groups, change from baseline to 6 months was analyzed using the paired $t$-test for weight, A1c, systolic blood pressure, and self-efficacy scores. McNemar's test was used for the binary results of the PHQ-9 score, while the Wilcoxon signed-rank test was used for self-rated health.

Analysis of covariance (ANCOVA) was used to assess between-group comparisons of baseline to 6month change for weight, A1c, systolic blood pressure, self-efficacy, and self-rated health. The 6month measure was the dependent variable. Group 


\begin{tabular}{|c|c|c|c|c|c|c|c|c|c|c|c|c|c|}
\hline \multirow[b]{2}{*}{$\begin{array}{l}\text { 1. HOW CONFIDENT DO YOU FEEL } \\
\text { THAT YOU CAN EAT YOUR } \\
\text { MEALS EVERY } 4 \text { TO } 5 \text { HOURS } \\
\text { EVERY DAY, INCLUDING } \\
\text { BREAKFAST EVERY DAY? }\end{array}$} & \multicolumn{7}{|c|}{ NOT AT ALL CONFIDENT } & \multicolumn{6}{|c|}{ TOTALLY CONFIDENT } \\
\hline & 1 & 2 & 2 & 3 & 4 & 5 & 5 & 6 & 7 & 8 & 9 & & 10 \\
\hline $\begin{array}{l}\text { 2. HOW CONFIDENT DO YOU FEEL } \\
\text { THAT YOU CAN FOLLOW YOUR } \\
\text { DIET WHEN YOU HAVE TO } \\
\text { PREPARE OR SHARE FOOD WITH } \\
\text { OTHER PEOPLE WHO DO NOT } \\
\text { HAVE DIABETES? }\end{array}$ & 1 & 2 & 2 & 3 & 4 & 5 & 5 & 6 & 7 & 8 & 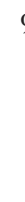 & & 10 \\
\hline $\begin{array}{l}\text { 3. HOW CONFIDENT DO YOU FEEL } \\
\text { THAT YOU CAN CHOOSE THE } \\
\text { APPROPRIATE FOODS TO EAT } \\
\text { WHEN YOU ARE HUNGRY (FOR } \\
\text { EXAMPLE, SNACKS)? }\end{array}$ & 1 & 2 & 2 & 3 & 4 & 5 & 5 & 6 & 7 & 8 & S & & 10 \\
\hline $\begin{array}{l}\text { 4. HOW CONFIDENT DO YOU FEEL } \\
\text { THAT YOU CAN EXERCISE } 15 \text { TO } \\
30 \text { MINUTES, } 4 \text { TO } 5 \text { TIMES A } \\
\text { WEEK? }\end{array}$ & 1 & 2 & 2 & 3 & 4 & 5 & 5 & 6 & 7 & 8 & 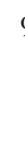 & ) & 10 \\
\hline $\begin{array}{l}\text { 5. HOW CONFIDENT DO YOU FEEL } \\
\text { THAT YOU CAN DO SOMETHING } \\
\text { TO PREVENT YOUR BLOOD } \\
\text { SUGAR LEVEL FROM DROPPING } \\
\text { WHEN YOU EXERCISE? }\end{array}$ & 1 & 2 & 2 & 3 & 4 & 5 & 5 & 6 & 7 & 8 & 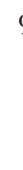 & 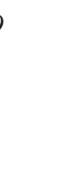 & 10 \\
\hline $\begin{array}{l}\text { 6. HOW CONFIDENT DO YOU FEEL } \\
\text { THAT YOU KNOW WHAT TO DO } \\
\text { WHEN YOUR BLOOD SUGAR } \\
\text { LEVEL GOES HIGHER OR LOWER } \\
\text { THAN IT SHOULD BE? }\end{array}$ & 1 & 2 & 2 & 3 & 4 & 5 & 5 & 6 & 7 & 8 & 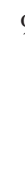 & 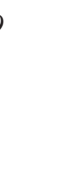 & 10 \\
\hline $\begin{array}{l}\text { 7. HOW CONFIDENT DO YOU FEEL } \\
\text { THAT YOU CAN JUDGE WHEN } \\
\text { THE CHANGES IN YOUR ILLNESS } \\
\text { MEAN YOU SHOULD VISIT THE } \\
\text { DOCTOR? }\end{array}$ & 1 & 2 & 2 & 3 & 4 & 5 & 5 & 6 & 7 & 8 & 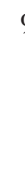 & 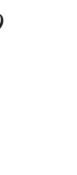 & 10 \\
\hline $\begin{array}{l}\text { 8. HOW CONFIDENT DO YOU FEEL } \\
\text { THAT YOU CAN CONTROL YOUR } \\
\text { DIABETES SO THAT IT DOES NOT } \\
\text { INTERFERE WITH THE THINGS } \\
\text { YOU WANT TO DO? }\end{array}$ & 1 & 2 & 2 & 3 & 4 & 5 & 5 & 6 & 7 & 8 & 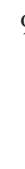 & ) & 10 \\
\hline $\begin{array}{l}\text { 9. IN GENERAL, WOULD YOU SAY } \\
\text { YOUR HEALTH IS: }\end{array}$ & Exce & llent $\mid \mathrm{V}$ & Very Goo & od $\mid$ & Good | & Fair |I & Poor & & & & & & \\
\hline $\begin{array}{l}\text { 10. HOW LIKELY ARE YOU TO } \\
\text { RECOMMEND ELIZABETH } \\
\text { FAMILY MEDICINE TO YOUR } \\
\text { FRIENDS AND FAMILY WHO } \\
\text { HAVE DIABETES? }\end{array}$ & $\begin{array}{c}\text { Very } \\
\text { V }\end{array}$ & $\begin{array}{l}\text { Likely } \\
\text { ery Unlik }\end{array}$ & $\begin{array}{l}\text { Somen } \\
\text { ikely }\end{array}$ & what & Likely & Neith & her Lik & k & Unlikely | & Son & & Unlik & \\
\hline $\begin{array}{l}\text { 11. WHAT COULD WE HAVE DONE } \\
\text { BETTER WHEN PROVIDING } \\
\text { DIABETES CARE? }\end{array}$ & & & & & & & & & & & & & \\
\hline $\begin{array}{l}\text { 12. WHICH OF THE FOLLOWING } \\
\text { BEST DESCRIBES YOUR RACE OR } \\
\text { THE RACE WITH WHICH YOU } \\
\text { BEST IDENTIFY? }\end{array}$ & $\begin{array}{r}\text { Ame } \\
\mathrm{H}\end{array}$ & $\begin{array}{l}\text { rican Ind } \\
\text { awaiian }\end{array}$ & $\begin{array}{l}\text { dian or } \\
\text { or Othe }\end{array}$ & $\begin{array}{l}\text { Alask } \\
\text { er Pac }\end{array}$ & $\begin{array}{l}\text { za Nati } \\
\text { cific Isl }\end{array}$ & $\begin{array}{l}\text { re } \mid \text { As } \\
\text { ander } \mid\end{array}$ & $\begin{array}{c}\operatorname{sian} \mid \mathrm{B} \\
\mid \text { Cauca }\end{array}$ & & $\begin{array}{l}\text { African A } \\
\text { Dther }\end{array}$ & Imer & & Native & \\
\hline $\begin{array}{l}\text { 13. WHAT DO YOU CONSIDER TO BE } \\
\text { YOUR ETHNICITY? }\end{array}$ & Hisp & anic or I & Latino | & Nor & -Hisp & nic or & r Latino & $\mathrm{O} \mid \mathrm{U}$ & nown & & & & \\
\hline $\begin{array}{l}\text { 14. WHAT IS YOUR HIGHEST LEVEL } \\
\text { OF EDUCATION? }\end{array}$ & $\begin{array}{r}\text { Less } \\
\mathrm{B}\end{array}$ & $\begin{array}{l}\text { than hig } \\
\text { chelor's }\end{array}$ & $\begin{array}{l}\text { gh schoc } \\
\text { s degree }\end{array}$ & $\begin{array}{l}\mathrm{ol} \mid \mathrm{H} \\
\mid \mathrm{Ma}\end{array}$ & $\begin{array}{l}\text { IS grac } \\
\text { ster's }\end{array}$ & $\begin{array}{l}\text { uate/C } \\
\text { egree }\end{array}$ & $\begin{array}{l}\text { GED } \mid \\
\mid \text { Profe }\end{array}$ & S & $\begin{array}{l}\text { ollege } \mid \mathrm{A} \\
\text { degree } \mid\end{array}$ & $\begin{array}{l}\text { Ssoci } \\
\text { Doct }\end{array}$ & & $\begin{array}{l}\text { egree } \mid \\
\text { degree }\end{array}$ & \\
\hline
\end{tabular}


Table 3. Patient Demographics

\begin{tabular}{|c|c|c|c|}
\hline & Intervention Group $(\mathrm{n}=36)$ & Control Group $(\mathrm{n}=38)$ & $P$ Value \\
\hline Age, mean (SD) & $55.4(9.7)$ & $54.6(11.9)$ & 0.75 \\
\hline Age, n (\%) & & & 0.75 \\
\hline 18 to 44 & $4(11.1)$ & $7(18.4)$ & \\
\hline 45 to 64 & $25(69.4)$ & $23(60.5)$ & \\
\hline $65+$ & $7(19.4)$ & $8(21.1)$ & \\
\hline Gender, n (\%) & & & 0.24 \\
\hline Male & $12(33.3)$ & $14(36.8)$ & \\
\hline Female & $24(66.7)$ & $24(63.2)$ & \\
\hline Ethnicity, n (\%) & & & 0.24 \\
\hline Hispanic or Latino & $0(0.0)$ & $3(7.9)$ & \\
\hline Non-Hispanic or Latino & $36(100.0)$ & $35(92.1)$ & \\
\hline Race, n (\%) & & & 0.42 \\
\hline African American & $32(88.9)$ & $35(92.1)$ & \\
\hline Caucasian & $4(11.1)$ & $2(5.3)$ & \\
\hline Other & $0(0.0)$ & $1(2.6)$ & \\
\hline Education, n (\%) & & & 0.14 \\
\hline$<$ High school & $6(16.6)$ & $11(29.0)$ & \\
\hline High school graduate/GED & $13(36.1)$ & $6(15.8)$ & \\
\hline Some college & $8(22.2)$ & $15(39.5)$ & \\
\hline Associate's cegree & $3(8.3)$ & $2(5.3)$ & \\
\hline College graduate or higher & $6(16.6)$ & $4(10.5)$ & \\
\hline BMI, n (\%) & & & 0.13 \\
\hline Underweight $<18.5$ & $0(0.0)$ & $0(0.0)$ & \\
\hline Normal 18.5 to 24.9 & $0(0.0)$ & $1(2.6)$ & \\
\hline Overweight 25.0 to 29.9 & $6(16.7)$ & $11(29.0)$ & \\
\hline Obese $\geq 30$ & $25(69.4)$ & $26(68.4)$ & \\
\hline Baseline smoking status (within last year) & & & 0.10 \\
\hline Smoker & $4(11.8)$ & $10(27.8)$ & \\
\hline Nonsmoker & $30(88.2)$ & $25(69.4)$ & \\
\hline
\end{tabular}

BMI, body mass index; SD, standard deviation.

assignment (intervention and control) was the primary independent variable, and the baseline measure was the covariate. For PHQ-9 (binary), the Breslow-Day test was used. The self-efficacy composite score was calculated as the average of items 1 to 8 (see Table 2). All analyses were performed using SAS Enterprise Guide 7.1 (SAS Institute Inc., Cary, NC). A $P$ value less than 0.05 was considered statistically significant.

\section{Results}

One hundred and eleven patients were enrolled between February 2014 and August 2018. The average patient age was 55 years; greater than $60 \%$ of the patients ranged in age from 45 to 64 years old. Sixty-six percent of the patients were female; greater than $80 \%$ were African American (see
Table 3). A1c values were similar in the intervention and 6-month delay (control) groups at baseline: $10.6 \%$ and $10.2 \%$, respectively (see Table 4 ). After 6 months from baseline, the intervention group showed a decrease in A1c of 2.4 compared with a decrease of 1.1 points in the control group, which was statistically significant $(P=.02)$. Mean self-efficacy scores increased 0.8 points to 8.0 in the intervention group $(P=.01)$, while there was a nonsignificant increase of 0.3 points in the control group $(P=.26)$ at 6 months. The effect of the intervention on self-efficacy scores did not reach statistical significance when compared with the observed change in the control group $(P=.05)$. A post hoc analysis showed mean decrease in A1c was greater in the intervention group among patients who had baseline PHQ-9 scores $>10$. Fifty-three out of 74 patients met the criteria for the SDM intervention. 
Table 4. Comparison of Clinical and Behavioral Outcomes at Baseline and 6-Month Visit Among Patients Enrolled in Diabetes Clinic Study

\begin{tabular}{|c|c|c|c|c|c|c|c|}
\hline & \multicolumn{3}{|c|}{$\begin{array}{l}\text { Intervention Group } \\
(\mathrm{n}=36)\end{array}$} & \multicolumn{3}{|c|}{$\begin{array}{c}\text { Control Group } \\
(\mathrm{n}=38)\end{array}$} & \multirow{2}{*}{$\begin{array}{l}\text { P Value for Between- } \\
\text { Group Comparison } \\
\text { of Baseline to 6- } \\
\text { Month Change }^{\dagger}\end{array}$} \\
\hline & Baseline & 6 Months & $\begin{array}{c}P \\
\text { Value* }\end{array}$ & Baseline & 6 Months & $\begin{array}{c}P \\
\text { Value* }\end{array}$ & \\
\hline Weight, mean (SD) & $219.3(56.4)$ & $217.0(56.0)$ & 0.73 & $230.6(61.1)$ & $226.0(52.5)$ & 0.51 & 1.0 \\
\hline Alc, mean (SD) & $10.6(1.4)$ & $8.2(1.7)$ & $<0.01$ & $10.2(1.8)$ & $9.1(2.0)$ & $<0.01$ & 0.02 \\
\hline SBP, mean (SD) & $129.8(14.1)$ & $128.6(19.3)$ & 0.84 & $134.1(20.6)$ & $128.5(22.3)$ & 0.06 & 0.49 \\
\hline PHQ-9, n (\%) & & & 1.0 & & & 0.08 & 0.17 \\
\hline$\leq 15$ & $29(96.7 \%)$ & $28(96.6 \%)$ & & $31(83.8 \%)$ & $31(93.9 \%)$ & & \\
\hline$>15$ & $1(3.3 \%)$ & $1(3.4 \%)$ & & $6(16.2 \%)$ & $2(6.1 \%)$ & & \\
\hline Self-efficacy, ${ }^{\ddagger}$ mean (SD) & $7.2(1.6)$ & $8.0(1.5)$ & 0.01 & $7.0(1.8)$ & $7.3(1.5)$ & 0.26 & 0.05 \\
\hline Self-rated health, n (\%) & & & 0.11 & & & 0.08 & 0.49 \\
\hline Excellent/Very Good & $7(19.4 \%)$ & $10(31.3 \%)$ & & $3(7.9 \%)$ & $9(25.0 \%)$ & & \\
\hline Good & $15(41.7 \%)$ & $13(40.6 \%)$ & & $16(42.1 \%)$ & $9(25.0 \%)$ & & \\
\hline Fair & $9(25.0 \%)$ & $7(21.9 \%)$ & & $17(44.7 \%)$ & $15(41.7 \%)$ & & \\
\hline Poor & $5(13.9 \%)$ & $2(6.3 \%)$ & & $2(5.3 \%)$ & $3(8.3 \%)$ & & \\
\hline
\end{tabular}

${ }^{*}$ Within-group change from baseline to 6 months was analyzed using the paired $t$-test for weight, A1c, SBP, and self-efficacy; McNemar's test for PHQ-9 (binary); and the Wilcoxon signed-rank test for self-rated health.

${ }^{\dagger}$ For weight, A1c, systolic blood pressure (SBP), self-efficacy, and self-rated health, between-group comparisons of baseline to 6 month change were performed using generalized linear models with the 6-month measure as the dependent variable, group (intervention, control) as the primary independent variable, and the baseline measure as a covariate. For PHQ-9 (binary), the Breslow-Day test was used for this purpose.

${ }^{\ddagger}$ The self-efficacy composite score was calculated as the average of items $1-8 .^{22}$

PHQ-9, 9-item Patient Health Questionnaire; SD, standard deviation.

The average number of weeks over 6 months that patients received the SDM intervention was 14 , with a standard deviation of $+/-7.4$ weeks. Data analyses were completed to determine the impact of the clinical interventions on patients randomized to the 6-month delayed-start arm. After 6 months of receiving the multidisciplinary approach, mean A1c values decreased from 10.2 at baseline to 9.0 $(P \leq 0.1)$ at month 12 . In the immediate start arm, mean A1c values decreased from 10.6 at baseline to $7.7(P \leq 0.01)$ at month 12 (see Table 5).

\section{Discussion}

The use of a multidisciplinary team approach in diabetes care was associated with a statistically significant improvement in mean A1c control and behavioral outcomes. This finding of a greater decrease in A1c is consistent with studies evaluating the role of interdisciplinary members in improving diabetes care. ${ }^{29,30}$ The design of our clinic used multiple disciplines along with techniques of SDM and motivational interviewing to address the many facets of diabetes management. ${ }^{16}$ The study showed a clinically significant difference in the change of A1c values after 6 months between the 2 groups. Self-efficacy scores in the intervention group at baseline versus 6 months were both clinically and statistically significant compared with those in the control group. An association was found between A1c and PHQ-9. The more depressed a person was at baseline in the intervention group, the more improvement he or she experienced in A1c at 6 months.

In addition to using the multidisciplinary team approach, successful implementation and sustainability of the diabetes clinic is due in part to the resources used to identify patient needs. By using a diabetes-specific PVA and SES to identify psychosocial and medication management needs, our multidisciplinary diabetes clinic team was able to minimize barriers and incorporate patients' needs as treatment goals. The SES provided a measurable method of understanding patients' self-management behaviors. Although we did not achieve our sample size goal based on a power calculation for the Alc outcome, and the intervention group did not achieve a 2-point difference from baseline to 
Table 5. Comparison of A1c at Baseline and 12-Month Visit Among Patients Enrolled in Diabetes Clinic Study

\begin{tabular}{|c|c|c|c|c|c|c|c|}
\hline & \multicolumn{3}{|c|}{ Intervention Group } & \multicolumn{3}{|c|}{ Control Group } & \multirow{2}{*}{$\begin{array}{l}P \text { Value for Between-Group } \\
\text { Comparison of Baseline to } \\
12-\text { Month Change }\end{array}$} \\
\hline & $\begin{array}{l}\text { Baseline } \\
(\mathrm{n}=36)\end{array}$ & $\begin{array}{l}12 \text { Months } \\
(\mathrm{n}=27)\end{array}$ & $P$ Value & $\begin{array}{l}\text { Baseline } \\
(\mathrm{n}=38)\end{array}$ & $\begin{array}{l}12 \text { Months } \\
(\mathrm{n}=28)\end{array}$ & $P$ Value & \\
\hline A1c, mean (SD) & $10.6(1.4)$ & $7.7(1.2)$ & $<0.01$ & $10.2(1.8)$ & $9.0(2.1)$ & $<0.01$ & $<0.01$ \\
\hline
\end{tabular}

SD, standard deviation.

month 6, the final sample size of 74 provided enough power to detect a difference as small as 1.2. Notably, the power analysis was based on a 2-sample $t$-test, and the final analysis was an ANCOVA. The SES increase of 0.8 led to a statistically significant increase in the intervention group. The betweengroup difference in SES for the intervention and control groups was not statistically significant. However, the clinical significance of improving confidence and behaviors in self-care was achieved.

In line with previous studies, these data highlight the usefulness of a long-term multidisciplinary diabetes clinic on A1c reduction and improved behavioral outcomes. Our pharmacist-led program showed A1c improvement, similar to a study showing patients not only lowering A1c but reaching their A1c goal faster. ${ }^{31}$ In addition, our study integrated behavioral health into treatment of poorly controlled type 2 diabetes, in line with a similar study that also found lower A1c values with behavioral health integration, as well as systolic blood pressure, compared with controls. ${ }^{32}$ In addition, a systematic review of multidisciplinary management found there was overall statistically improved A1c values as well as improvement in health-related quality of life, patient self-care abilities, and patient knowledge of diabetes. ${ }^{33}$ Practices that have a different mix of health care professionals may benefit from reviewing standard 5 of the National Standards for Diabetes Self-Management Education and Support. ${ }^{17}$ This standard discusses how to assemble a successful team using available clinical resources. Collaborative practice agreements may also be a great cost-neutral strategy for improving skills within a team. Literature highlights the clinical usefulness of collaborative practice agreements between clinical pharmacists and physician practices. ${ }^{32,34}$ Primary care practices not yet collaborating with professional health care programs can easily begin a symbiotic partnership. Universities with health care professional programs are frequently looking for patient care sites where faculty can practice in their respective specialty area while providing continuous learning experiences for learners. In exchange for providing a practice site for health professional students to complete their supervised training, licensed faculty work under a collaborative agreement to implement beneficial clinical services while serving as the core preceptor for their learners.

\section{Limitations}

This strategy of using a multidisciplinary diabetes clinic to manage chronically uncontrolled patients is not without limitations. One limitation was the strong teaching component embedded within the multidisciplinary diabetes study that allowed potential cross contamination where provider exposure to both the control and intervention groups may have led to improved management in the delayed arm patients. Resident physicians who rotated through the diabetes clinic may have also served as the primary care providers for patients randomized to the delayed-start arm. Loss to follow-up was also higher than expected; our complete case analysis included only 74 of the 111 patients who were randomized. Common reasons for loss to follow-up included change in insurance or primary care provider, transportation challenges, and scheduling conflicts. Comparisons between patients with 6month follow-up data and those without showed that these patients did not differ significantly on measured variables. The intervention and control groups in our final analysis sample also did not differ significantly on measured variables. However, loss to follow-up may have led to differences in unmeasured characteristics between the study groups, or between participants with 6-month follow-up data and those without such data, so selection bias remains a possibility.

\section{Conclusions}

Organizing a multidisciplinary approach to diabetes care can provide a much-needed resource for 
managing diabetes. This study provides a strategy for implementing a multidisciplinary approach to diabetes management in any primary care practice using a pharmacist, social worker, physicians, behavioral health counselors, clinical care coordinator, and nurse. Despite these data, gaps in evidence remain, especially with respect to long-term outcomes and intervention sustainability.

We would like to thank all of the members of the multidisciplinary diabetes clinic team for their support and contributions to the clinic design; Lakesha Beasley, Laura Staton, Steven Greenberg, Kenniesha Spencer, Dellyse Bright, Jewell Carr, Allison Bickett, and Rebecca Hayes.

To see this article online, please go to: http://jabfm.org/content/ 34/3/579.full.

\section{References}

1. Lin J, Thompson TJ, Cheng YJ, et al. Projection of the future diabetes burden in the United States through 2060. Popul Health Metr 2018;16:9.

2. American Diabetes Association. Economic costs of diabetes in the U.S. 2017. Diabetes Care 2018;41. https://www.ncbi.nlm.nih.gov/pmc/articles/pmid/ 29567642/.

3. Nouwen A, Winkley K, Twisk J, et al. Type 2 diabetes mellitus as a risk factor for the onset of depression: a systematic review and meta-analysis. Diabetologia 2010;53:2480-6.

4. Egede LE, Zheng D, Simpson K. Comorbid depression is associated with increased health care use and expenditures in individuals with diabetes. Diabetes Care 2002;25:464-70.

5. Bhattacharya R, Shen C, Wachholtz AB, Dwibedi N, Sambamoorthi U. Depression treatment decreases healthcare expenditures among working age patients with comorbid conditions and type 2 diabetes mellitus along with newly-diagnosed depression. BMC Psychiatry 2016;16:247.

6. Stark Casagrande S, Fradkin JE, Saydah SH, Rust $\mathrm{KF}$, Cowie CC. The prevalence of meeting A1C, blood pressure, and LDL goals among people with diabetes, 1988-2010. Diabetes Care 2013;36: 2271-9.

7. Ali MK, Bullard KM, Saaddine JB, Cowie CC, Imperatore G, Gregg EW. Achievement of goals in U.S. diabetes care, 1999-2010. N Engl J Med 2013;368:1613-24.

8. Jiang X, Wang J, Lu Y, Jiang H, Li M. Self-efficacy-focused education in persons with diabetes: a systematic review and meta-analysis. Psychol Res Behav Manag 2019;12:67-79.

9. Adler RN, Harlan DM, Diabetes Center of Excellence UMass Memorial Health Care. Diabetes: 8 strategies to put into practice. J Fam Pract 2013;62:542-7.
10. Nichols GA, McBurnie M, Paul L, et al. The high prevalence of diabetes in a large cohort of patients drawn from safety net clinics. Prev Chronic Dis 2016;13:E78.

11. American Diabetes Association. Standards of medical care in diabetes-2020 abridged for primary care providers. Clin Diabetes 2020;38:10-38.

12. McGill M, Blonde L, Chan JCN, et al. The interdisciplinary team in type 2 diabetes management: challenges and best practice solutions from realworld scenarios. J Clin Transl Endocrinol 2017; 7:21-7.

13. Benedict AW, Spence MM, Sie JL, et al. Evaluation of a pharmacist-managed diabetes program in a primary care setting within an integrated health care system. JMCP 2018;24:114-22.

14. Chwastiak LA, Jackson SL, Russo J, et al. A collaborative care team to integrate behavioral health care and treatment of poorly-controlled type 2 diabetes in an urban safety net primary care clinic. Gen Hosp Psychiatry 2017;44:10-5.

15. Helou N, Dwyer A, Shaha M, Zanchi A. Multidisciplinary management of diabetic kidney disease: a systematic review and meta-analysis. JBI Database System Rev Implement Rep 2016;14:169_ 207.

16. Tapp H, Phillips SE, Waxman D, Alexander M, Brown R, Hall M. Multidisciplinary team approach to improved chronic care management for diabetic patients in an urban safety net ambulatory care clinic. J Am Board Fam Med 2012;25:245-6.

17. Beck J, Greenwood DA, Blanton L, et al. 2017 national standards for diabetes self-management education and support. Diabetes Spectr 2017;30: 301-14.

18. Lorig K, Ritter PL, Villa FJ, Armas J. Communitybased peer-led diabetes self-management: a randomized trial. Diabetes Educ 2009;35:641-51.

19. Cohen LB, Taveira TH, Khatana SA, Dooley AG, Pirraglia PA, Wu WC. Pharmacist-led shared medical appointments for multiple cardiovascular risk reduction in patients with type 2 diabetes. Diabetes Educ 2011;37:801-12.

20. Sadur CN, Moline N, Costa M, et al. Diabetes management in a health maintenance organization: efficacy of care management using cluster visits. Diabetes Care 1999;22:2011-7.

21. Munshi MN, Segal AR, Suhl E, et al. Assessment of barriers to improve diabetes management in older adults: a randomized controlled study. Diabetes Care 2013;36:543-9.

22. Sturt J, Hearnshaw H, Wakelin M. Validity and reliability of the DMSES UK: a measure of self-efficacy for type 2 diabetes self-management. Primary Health Care 2010;11:374-81.

23. Nuti L, Turkcan A, Lawley MA, Zhang L, Sands L, McComb S. The impact of interventions on 
appointment and clinical outcomes for individuals with diabetes: a systematic review. BMC Health Serv Res 2015;15:355.

24. Tamhane S, Rodriguez-Gutierrez R, Hargraves I, Montori VM. Shared decision-making in diabetes care. Curr Diab Rep 2015;15:112.

25. Branda ME, LeBlanc A, Shah ND, et al. Shared decision making for patients with type 2 diabetes: a randomized trial in primary care. BMC Health Serv Res 2013;13:301.

26. Kroenke K, Spitzer RL, Williams JB. The PHQ-9: validity of a brief depression severity measure. J Gen Intern Med 2001;16:606-13.

27. Look Ahead Research Group, Wing RR, Bolin P, et al. Cardiovascular effects of intensive lifestyle intervention in type 2 diabetes. $\mathrm{N}$ Engl J Med 2013;369:145-54.

28. Evert AB, Dennison M, Gardner CD, et al. Nutrition therapy for adults with diabetes or prediabetes: a consensus report. Diabetes Care 2019; 42:731-54.

29. Steven M, Lamie JC, Baillod SD, Rockafellow MB, Gibbs DS. An interdisciplinary team approach to managing diabetes in a patient-centered medical home. Diabetes 2018;67:700.
30. Lau R, Stevenson F, Ong BN, et al. Achieving change in primary care-causes of the evidence to practice gap: systematic reviews of reviews. Implement Sci 2016;11:40.

31. Willens D, Cripps R, Wilson A, Wolff K, Rothman R. Interdisciplinary team care for diabetic patients by primary care physicians, advanced practice nurses, and clinical pharmacists. Clinical Diabetes 2011;29:60-8.

32. Simpson SH, Majumdar SR, Tsuyuki RT, Lewanczuk RZ, Spooner R, Johnson JA. Effect of adding pharmacists to primary care teams on blood pressure control in patients with type 2 diabetes: a randomized controlled trial. Diabetes Care 2011; 34:20-6.

33. Nam S, Chesla C, Stotts NA, Kroon L, Janson SL. Barriers to diabetes management: patient and provider factors. Diabetes Res Clin Pract 2011;93: $1-9$.

34. Ladhani NN, Majumdar SR, Johnson JA, et al. Adding pharmacists to primary care teams reduces predicted long-term risk of cardiovascular events in type 2 diabetic patients without established cardiovascular disease: results from a randomized trial. Diabet Med 2012;29:1433-9. 